\title{
Activation of C-fiber nociceptors by low-power diode laser
}

\author{
Ativação por laser de diodo de baixa potência de nociceptores relacionados a fibras C \\ Eduardo Azevedo 1 , Andressa Silva', Raquel Martins', Monica L. Andersen'1, Sergio Tufik', Gilberto M. Manzano²
}

\begin{abstract}
Objective: The evaluation of selective activation of C-fibers to record evoked potentials using the association of low-power diode laser $(810 \mathrm{~nm})$, tiny-area stimulation and skin-blackening. Method: Laser-evoked potentials (LEPs) were obtained from 20 healthy young subjects. An aluminum plate with one thin hole was attached to the laser probe to provide tiny-area stimulation of the hand dorsum and the stimulated area was covered with black ink. Results: The mean intensity used for eliciting the ultra-late laser-evoked potential (ULEP) was $70 \pm 32 \mathrm{~mW}$. All subjects showed a clear biphasic potential that comprised a negative peak (806 $\pm 61 \mathrm{~ms}$ ) and a positive deflection $(1033 \pm 60 \mathrm{~ms})$, corresponding to the ULEP related to C-fiber activation. Conclusion: C-fiber-evoked responses can be obtained using a very low-power diode laser when stimulation is applied to tiny areas of darkened skin. This strategy offers a non-invasive and easy methodology that minimizes damage to the tissue.
\end{abstract}

Keywords: laser-evoked potentials, C-fibers, nociception, pain perception.

\section{RESUMO}

Objetivo: Avaliação da ativação de fibras C para o registro de potenciais evocados utilizando-se laser de baixa potência, áreas pequenas de estimulação e escurecimento da pele. Método: Potenciais evocados foram obtidos de 20 sujeitos. Uma placa de alumínio com uma pequena abertura foi acoplada à ponteira do laser para estimular área escurecida do dorso da mão. Resultados: A intensidade média utilizada para estimulação foi de $70 \pm 32 \mathrm{~mW}$. Todos os sujeitos apresentaram respostas claras compreendendo dois picos um negativo (806 $\pm 61 \mathrm{ms)}$ seguido por outro positivo (1033 $\pm 60 \mathrm{~ms}$ ), correspondendo ao potencial evocado tardio por estimulação de fibras C. Conclusão: Respostas de fibras $C$ podem ser obtidas utilizando-se laser de baixa potência quando a estimulação é aplicada a pequenas áreas de pele escurecida. Esta estratégia oferece uma metodologia não invasiva que minimiza danos teciduais.

Palavras-chave: potenciais evocados a laser, fibras C, nocicepção, percepção dolorosa.

The criteria for diagnosis of definite neuropathic pain depend on a plausible neuroanatomic distribution of the pain, a history suggestive of somatosensory lesion or disease and at least one objective confirmatory test of the existence of such relevant somatosensory lesion or disease ${ }^{1}$. Somatosensory evoked potentials (SEPs) and laser evoked potentials (LEPs) are becoming "standards" to document possible involvement of the neural systems in patients with neuropathic pain: the sensitivity of LEP to small lesions on the involved pathways are conferring to it medical legal value in some European countries $^{2}$. Although exquisitely sensitive to spinothalamic impairments, LEPs are considered as a supportive tool to diagnose small fiber neuropathies (given their poor localization value $)^{3}$. These observations suggest that the search for alternative stimulus sources to obtain LEPs, aiming to reduce the risks of complications (e.g. skin burns) and the costs of the procedure, are important to increase the availability of these exams; further, the stimulus should be able to allow separate evaluations of $\mathrm{A} \delta$ and $\mathrm{C}$ fibers.

Laser heat stimulators have been extensively used to study time-locked nociception responses, as they provide a near-ideal method to selectively activate cutaneous $\mathrm{A} \delta$-fiber and C-fiber nociceptors. The high power outputs of lasers, which allow fast heat ramps, concomitantly activate these two systems and produce a dual perception compatible with conduction in small myelinated $A \delta$ and unmyelinated $\mathrm{C}$ fibers ${ }^{4}$.

Cortical responses to high intensity stimulation, however, do not reflect such dual activation. Scalp recordings of LEP show a major negative-positive wave (N2-P2) in the latency range of 200-400 ms when stimulating the hand dorsum. These results have been associated with $A \delta$-fiber activity,

1 Universidade Federal de São Paulo, Departamento de Psicobiologia, Sao Paulo SP, Brazil;

${ }^{2}$ Universidade Federal de São Paulo, Setor de Neurofisiologia Clínica, Sao Paulo SP, Brazil.

Correspondence: Gilberto Mastrocola Manzano; Rua Botucatu, 603;04023-062 São Paulo SP, Brasil; E-mail: gmmanzano@hotmail.com.br

Conflict of interest: There is no conflict of interest to declare.

Received 05 October 2015; Accepted 28 October 2015. 
with none of the responses at latencies related to signals ascending through C-fibers ${ }^{5,6}$. Responses mediated exclusively by C-fibers, an ultra-late LEP (ULEP) at a latency of about $1000 \mathrm{~ms}$, can be elicited only by special methods that allow their selective activation, such as low-power heating of the skin below $A \delta$ threshold ${ }^{7,8}$, pressure nerve block ${ }^{9}$ or the stimulation of tiny skin surfaces ${ }^{10}$. It is not clear yet why concomitant activation of $\mathrm{A} \delta$ - and C-fibers does not allow the individualization of both late and ultra-late LEPs $^{6,11,12,13}$, interestingly, depending on the intensity of stimulation, both responses can occasionally be observed ${ }^{7}$, also related to this issue is the recent suggestion that laser pulses may also occasionally, in special circumstances, lead to tactile sensations ${ }^{14}$.

Among the methods used to selectively activate C-fibers, stimulation of tiny areas of skin requires few adjustments of the laser stimulator. This process can be implemented by interposing a thin plate, drilled with one or more small holes, between the stimulus probe and the skin surface in order to act as a spatial filter for the laser beam ${ }^{15,16,17}$. The principle of this method is based on higher innervation density of C-fiber terminals on the skin (three or four times more numerous than $\mathrm{A} \delta$-fibers in humans), resulting in a higher probability of stimulating the terminals of $\mathrm{C}$-fibers than those of $\mathrm{A} \delta$-fibers ${ }^{18}$.

Different laser emission sources have been used to elicit evoked responses in clinical studies, with their practical differences relying on the physical properties of the different wavelengths: argon (488-515 nm), copper vapor (510-577 nm), neodymium-YAG (1,064 nm), thulium-YAG $(2,000 \mathrm{~nm})$ and diode lasers (700-1,000 nm); the most commonly used is the infrared $\mathrm{CO}_{2}$ laser, which has been supported by a large number of studies ${ }^{19}$. However, as flexible optical fibers do not conduct the $\mathrm{CO}_{2}$ infrared heat well, the use of extra devices to orient the laser target over the skin becomes necessary.

Developments in the field of semiconductors have turned diode lasers into a good choice for pain stimulation in basic and clinical applications. Practical advantages of this laser include its small size, low price and ability to transmit its output heat pulse via a flexible quartz fiber. One disadvantage of diode lasers is their sensitivity to skin pigmentation. Variations in pigmentation alter the penetration depth of the heat pulse and, consequently, the amount of energy delivered to the receptors ${ }^{20,21}$. To minimize this variability, some studies have blackened the target area of the hand dorsum using carbon black with a high emissivity factor, assuring that energy is absorbed uniformly on the superficial layer of the skin and can reach the nearby receptors by passive heat conduction $^{22,23}$. To date, only a few investigators have focused on human LEP elicited by diode lasers, which have applied high-power intensities to obtain only $\mathrm{A} \delta$ responses ${ }^{24,25}$ or have observed simultaneous $\mathrm{A} \delta$ - and $\mathrm{C}$-fiber responses that were restricted to a single subject ${ }^{26}$.

Previously we were able to record LEPs related to A $\delta$ fibers using a low power diode laser after skin blackening ${ }^{7}$, In the present study, we investigated the feasibility of selectively activating C-fiber responses in healthy volunteers using a low-power diode laser applied to tiny areas of blackened skin.

\section{METHOD}

\section{Subjects}

Twenty healthy Caucasians volunteers participated in this study (18 males, 2 females, $26.3 \pm 4.5$ years old). They were previously screened for medical and neurological conditions that might affect normal somatosensory perception, as well as for smoking, alcohol and substance abuse. All subjects gave written informed consent before participating in this study, which had the approval of the Ethics Committee of the Federal University of Sao Paulo (UNIFESP-1592/06).

\section{Experimental procedure}

Subjects were first presented with the stimulation device and an explanation of the experimental procedures. During the experiments, they stayed in a quiet room on a reclining armchair and were instructed to remain awake with their eyes open, staring at a point on the wall in front of them to minimize eye movements. The right forearm and hand of the volunteers were immobilized over a table by a specially designed orthosis. The experiment lasted approximately 30 minutes per subject; during this period, the temperature of the experimental room was kept constant.

\section{Laser stimulation}

The stimulus consisted of short laser pulses of $50 \mathrm{~ms}$ duration, applied to the dorsum of the right hand by a diode laser device of $810 \mathrm{~nm}$ wavelength (FTC2000, Opto Laser). The stimulated area of the skin was previously blackened with water-based ink (high emissivity factor). To selectively activate the $\mathrm{C}$-fibers, we attached an aluminum plate that had one thin hole drilled ( $0.1 \mathrm{~mm}$ diameter) at the top of the stimulus probe. A servomotor device, controlled by a PC running LabView software (National Instruments, USA), was developed to program the stimulation protocol and to slightly displace the target site of the collimated beam between trials; the stimulus spot moved in a circular pathway with a diameter of approximately $6 \mathrm{~cm}$ on the dorsum of the hand to avoid receptors adaptation. The laser output power was rechecked using an optical meter after the stimulator system was assembled to consider losses imposed by the transmitting optical fiber, the collimator lens and the aluminum dot plate.

\section{Experimental procedure}

Before EEG acquisition, subjects were presented with single laser pulses with increasing intensities - starting from a very low intensity level (sub-threshold) and steadily increasing until a warm sensation could be perceived by the volunteer. This intensity was noted and designated the warmth perception threshold (WPT). 
One-hundred laser pulses were automatically delivered to subjects with an inter-stimulus interval of $5 \mathrm{~s}$. The laser intensity was constant at approximately twice the perception threshold. After stimulation, volunteers were prompted to rate the intensity of perception by pointing to a visual analog scale (VAS), ranging from 0 (no sensation) to 10 (maximum pain). In addition, to focus their attention on the stimulation site, they were asked to mentally count the perceived number of total laser pulses.

\section{Laser-evoked potential}

Brain electrical activity was recorded on $\mathrm{Cz}$ referenced to linked earlobes, using polysomnography equipment (S7000, Embla Systems, USA) at the facilities of the Sleep Institute. The sampling rate was set to $200 \mathrm{~Hz}$, and the internal ana$\log$ filtering of the equipment was set to $0.3-90 \mathrm{~Hz}$, besides the $60 \mathrm{~Hz}$ powerline rejection. To monitor ocular movements and eye-blinks and to discard EEG contaminated trials, electrooculographic (EOG) signals were simultaneously recorded with surface electrodes. Impedances were kept bellow $5 \mathrm{k} \Omega$. Signal processing routines were written in Matlab software (Mathworks, USA) to perform off-line averaging of the EEG sweeps and calculate the laser-evoked potential.

\section{RESULTS}

The WPT was $41 \pm 25 \mathrm{~mW}$ for the set of volunteers and the mean intensity used for their stimulation was $70 \pm 32 \mathrm{~mW}$. Subjects often described the perception of their stimulus as a warm sensation or a bearable pain.

Repetitive laser stimulation elicited clear and reproducible ULEPs for all the subjects (Figure 1) and was characterized by a negative-positive deflection at the latencies of $806 \pm 61 \mathrm{~ms}(\mathrm{~N} 2)$ and $1033 \pm 60 \mathrm{~ms}$ (P2). The low inter-individual variability of N2-P2 components resulted in a well-defined grand average (Figure 2).

The VAS results, which indicate the mean perceived laser intensity perception, varied by a wide range ( $2 \pm 2)$, most likely reflecting their subjective nature. The pulse count was $66 \pm 20$, corresponding to approximately $66 \%$ of the total pulses in each set (100). These results are summarized in the Table.

\section{DISCUSSION}

Our results indicate that reproducible C-fiber evoked responses can be obtained using a low-power diode laser applied to tiny areas of blackened skin. Using this stimulation protocol, the ULEP was consistently elicited with latencies in accordance with those reported in other studies that used high-power $\mathrm{CO}_{2}$ lasers applied to small areas of natural (non-blackened) skin ${ }^{10,27,28,29,30}$. The few investigators that have previously employed the darkening procedure reported

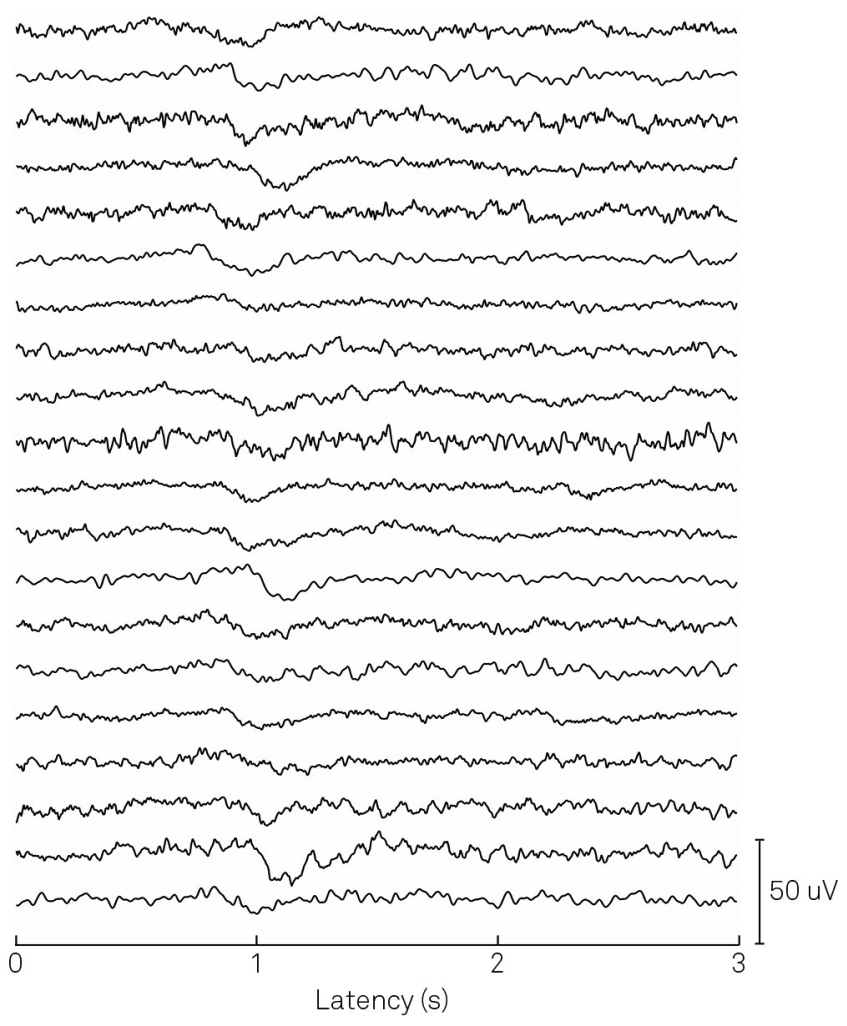

Figure 1. Evoked potentials of the subjects. Evoked potentials following laser stimulation of the twenty subjects. The ultra-late component of LEP can be consistently observed at a latency of $\sim 1 \mathrm{~s}$.

only $\mathrm{A} \delta$ responses after high-intensity stimulation in three subjects ${ }^{5}$ or have not focused on laser-evoked potentials, but on subjective pain and thermal thresholds ${ }^{21,31}$. In a previous study we were also able to study A $\delta$ responses using the same methodology except for a larger area of stimulation?

When comparing our data with other ULEP studies, one must be aware of the differences in the referred stimulus intensities. In the present investigation, laser output power was rechecked after the aluminum plate was installed, and a calibration curve was constructed to correct the output power indicated by the equipment. Somewhat surprisingly, real

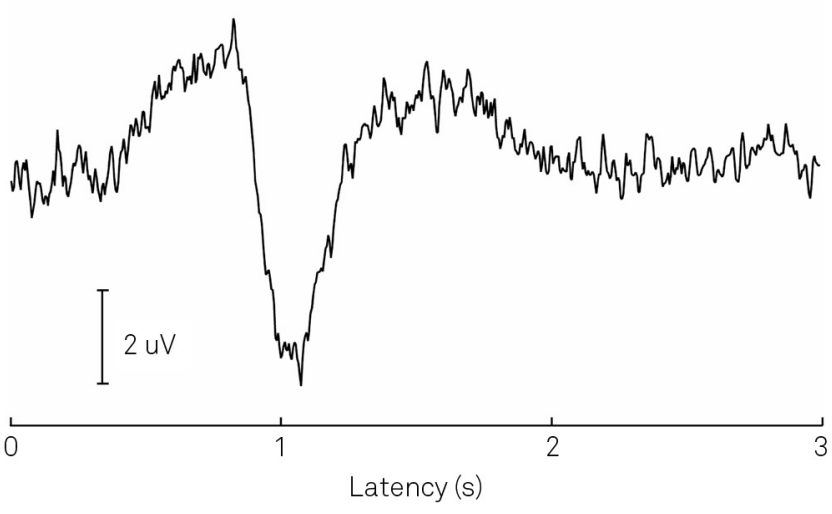

Figure 2. Grand average. Grand average of the evoked responses. 
Table. Results obtained after laser stimulation of the subjects' right hand.

\begin{tabular}{lc}
\hline & Mean \pm SD \\
\hline WPT (mW) & $41 \pm 25$ \\
VAS (0-10) & $2 \pm 2$ \\
Stimulation intensity (mW) & $70 \pm 32$ \\
Ratio : Stimulation Intensity / WPT & $1.9 \pm 0.2$ \\
Latency N2 (ms) & $806 \pm 61$ \\
Latency P2 (ms) & $1,033 \pm 60$ \\
Pulse count (\%) & $66 \pm 20$ \\
\hline WPT: warm perceptual threshold; VAS: visual analogic scale; \\
SD: standard deviation.
\end{tabular}

intensities were approximately $10 \%$ of those displayed by the equipment. Most of the output energy was, in fact, blocked by the small hole in the aluminum plate - when the plate was removed, the measured power increased to $55 \%$ of the equipment's indication; the remaining losses were most likely due to the collimator lens and the optical fiber transmission. Moreover, darkening of the skin is known to drastically modify the heat pattern on the laser spot. Leandri and colleagues ${ }^{23}$ carried out a detailed measurement of the skin temperature during and immediately after irradiation of white and blackened skin with $\mathrm{CO}_{2}$ and Nd:YAP lasers. Their report indicates that this procedure matched the thermal effects of both lasers, homogenizing the way receptors at different depths are activated. When the same stimulus was delivered to both types of skin, temperatures and perceived pain were consistently higher for the blackened skin. Consequently, lower stimulus intensities can be employed to elicit C-fiber responses, which reduces the possibility of damage to the skin. We used a very low intensity range that was near the evoked response threshold, as suggested by the low power (in the $\mathrm{mW}$ range) and confirmed by the relatively low number of laser pulses counted by the volunteers (66\%). With such approach, none of the subjects in our study developed superficial burns on the skin and clear evoked reponses were recorded in all of them. It should be pointed out that even dealing with low power lasers, care need to be exercised since noxious levels of stimulation are intimately related to potential or actual tissue injury.

In conclusion, the present investigation showed that combining a skin-blackening procedure with a tiny area of stimulation technique allows the selective activation of C-fiber evoked responses by the use of a very low-power diode laser. This strategy offers a non-invasive and easy to implement methodology that minimizes damage to the tissue.

\section{References}

1. Treede RD, Jensen TS, Campbell JN, Cruccu G, Dostrovsky JO, Griffin JW et al. Neuropathic pain: redefinition and a grading system for clinical and research purposes. Neurology. 2008;70(18):1630-5. doi:10.1212/01.wnl.0000282763.29778.59

2. Garcia-Larrea L. Objective pain diagnostics: clinical neurophysiology. Neurophysiol Clin. 2012;42(4):187-97. doi:10.1016/j.neucli.2012.03.001

3. Merkies ISJ, Faber CG, Lauria G. Advances in diagnostics and outcome measures in peripheral neuropathies. Neurosci Lett. 2015;596:3-13. doi:10.1016/j.neulet.2015.02.038

4. Bromm B, Treede RD. Nerve fibre discharges cerebral potentials and sensations induced by $\mathrm{CO} 2$ laser stimulation. Hum Neurobiol. 1984;3(1):33-40.

5. Kakigi R, Inui K, Tamura Y. Electrophysiological studies on human pain perception. Clin Neurophysiol. 2005;116(4):743-63. doi:10.1016/j.clinph.2004.11.016

6. Mouraux A, Guérit JM, Plaghki L. Refractoriness cannot explain why C-fiber laser-evoked brain potentials are recorded only if concomitant Adelta-fiber activation is avoided. Pain. 2004;112(1-2):16-26. doi:10.1016/j.pain.2004.05.024

7. Azevedo E, Manzano GM, Silva A, Martins R, Andersen ML, Tufik $S$. The effects of total and REM sleep deprivation on laser-evoked potential threshold and pain perception. Pain. 2011;152(9):2052-8. doi:10.1016/j.pain.2011.04.032

8. Cruccu G, Pennisi E, Truini A, lannetti GD, Romaniello A, Le Pera D et al. Unmyelinated trigeminal pathways as assessed by laser stimuli in humans. Brain. 2003;126(10):2246-56. doi:10.1093/brain/awg227

9. Bromm B, Neitzel H, Tecklenburg A, Treede RD. Evoked cerebral potential correlates of C-fibre activity in man. Neurosci Lett. 1983;43(1):109-14. doi:10.1016/0304-3940(83)90137-4

10. Bragard D, Chen AC, Plaghki L. Direct isolation of ultra-late (C-fibre) evoked brain potentials by $\mathrm{CO} 2$ laser stimulation of tiny cutaneous surface areas in man. Neurosci. Lett. 1996;209(2):81-4. doi:10.1016/0304-3940(96)12604-5

11. Mouraux A, Guérit JM, Plaghki L. Non-phase locked electroencephalogram (EEG) responses to $\mathrm{CO}_{2}$ laser skin stimulation may reflect central interactions between $\mathrm{A} 1$ - and C-fibre afferent volleys. Clin Neurophysiol. 2003;114(4):710-22. doi:10.1016/S1388-2457(03)00027-0

12. Tran TD, Matre D, Casey KL. An inhibitory interaction of human cortical responses to stimuli preferentially exciting Adelta or C fibers. Neuroscience. 2008;152(3):798-808. doi:10.1016/j.neuroscience.2007.11.050

13. Truini A, Galeotti F, Cruccu G, Garcia-Larrea L. Inhibition of cortical responses to Ad inputs by a preceding C-related response: testing the "First come, first served" hypothesis. Pain. 2007;131(3):341-7. doi:10.1016/j.pain.2007.06.023

14. Jun JH, ParkJR, Kim SP, Min Bae Y, Park JY, Kim HS et al. Laser-induced thermoelastic effects can evoke tactile sensations. Sci Rep. 2015;5:11016. doi:10.1038/srep11016

15. Qiu Y, Inui K, Wang X, Tran TD, Kakigi R. Conduction velocity of the spinothalamic tract in humans as assessed by $\mathrm{CO}_{2}$ laser stimulation of C-fibers. Neurosci Lett. 2001;311(3):181-4. doi:10.1016/S0304-3940(01)02170-X

16. Qiu Y, Noguchi $Y$, Honda $M$ et al. Brain processing of the signals ascending through unmyelinated $\mathrm{C}$ fibers in humans: an event-related functional magnetic resonance imaging study. Cereb Cortex. 2006;16(9):1289-95. doi:10.1093/cercor/bhj071

17. Tran TD, Lam K, Hoshiyama M, Kakigi R. A new method for measuring the conduction velocities of Abeta-, Adelta- and C-fibers following electric and $\mathrm{CO}_{(2)}$ laser stimulation in humans. Neurosci Lett. 2001;301(3):187-90. doi:10.1016/S0304-3940(01)01639-1 
18. Hallin RG, Wiesenfeld Z. A standardized electrode for percutaneous recording of $A$ and $C$ fibre units in conscious man. Acta Physiol Scand. 1981;113(4):561-3. doi:10.1111/j.1748-1716.1981.tb06940.x

19. Cruccu G, Anand P, Attal N, Garcia-Larrea L, Haanpää M, Jørum E et al. EFNS guidelines on neuropathic pain assessment. Eur J Neurol. 2004;11(3):153-62. doi:10.1111/j.1468-1331.2004.00791.x

20. Plaghki L, Mouraux A. How do we selectively activate skin nociceptors with a high power infrared laser? Physiology and biophysics of laser stimulation. Neurophysiol Clin. 2003;33(6):269-77. doi:10.1016/j.neucli.2003.10.003

21. Arendt-Nielsen L, Bjerring P. Sensory and pain threshold characteristics to laser stimuli.J Neurol Neurosurg Psychiatry. 1988;51(1):35-42. doi:10.1136/jnnp.51.1.35

22. Arendt-Nielsen L, Chen CAN. Lasers and other thermal stimulators for activation of skin nociceptors in humans. Neurophysiol Clin. 2003;33(6):259-68. doi:10.1016/j.neucli.2003.10.005

23. Leandri M, Saturno M, Spadavecchia L, lannetti GD, Cruccu G, Truini A. Measurement of skin temperature after infrared laser stimulation. Neurophysiol Clin. 2006;36(4):207-18. doi:10.1016/j.neucli.2006.08.004

24. Durak K, Chen AC, Arendt-Nielsen L. 3D topographic study of the diode laser evoked potentials (LEPS) to painful stimulation of the trigeminal sensory area. Brain Topogr. 2004;16(3):133-8. doi:10.1023/B:BRAT.0000019182.45048.ba

25. Gülsoy M, Durak K, Kurt A, Karamürsel S, Cilesiz I. The 980-nm diode laser as a new stimulant for laser evoked potentials studies. Lasers Surg Med. 2001;28(3):244-7. doi:10.1002/lsm.1045
26. Greffrath W, Nemenov MI, Schwarz S, Baumgärtner U, Vogel H, Arendt-Nielsen L et al. Inward currents in primary nociceptive neurons of the rat and pain sensations in humans elicited by infrared diode laser pulses. Pain. 2002;99(1-2):145-55. doi:10.1016/S0304-3959(02)00071-4

27. Opsommer E, Guérit JM, Plaghki L. Exogenous and endogenous components of ultralate (C-fibre) evoked potentials following $\mathrm{CO} 2$ laser stimuli to tiny skin surface areas in healthy subjects. Neurophysiol Clin. 2003;33(2):78-85. doi:10.1016/S0987-7053(03)00007-8

28. Opsommer E, Weiss T, Plaghki L, Miltner WH. Dipole analysis of ultralate (C-fibres) evoked potentials after laser stimulation of tiny cutaneous surface areas in humans. Neurosci Lett. 2001;298(1):41-4. doi:10.1016/S0304-3940(00)01718-3

29. Qiu Y, Inui K, Wang X, Tran TD, Kakigi R. Effects of attention distraction and sleep on $\mathrm{CO}(2)$ laser evoked potentials related to C-fibers in humans. Clin Neurophysiol. 2002;113(10):1579-85. doi:10.1016/S1388-2457(02)00216-X

30. Valeriani M, Le Pera D, Niddam D, Chen AC, Arendt-Nielsen L. Dipolar modelling of the scalp evoked potentials to painful contact heat stimulation of the human skin. Neurosci Lett. 2002;318(1):44-8. doi:10.1016/S0304-3940(01)02466-1

31. Sutton JA, Gillin WP, Grattan TJ, Clarke GD, Kilminster SG. A new laser pain threshold model detects a faster onset of action from a liquid formulation of $1 \mathrm{~g}$ paracetamol than an equivalent tablet formulation. Br J Clin Pharmacol. 2002;5(1)3:43-7. doi:10.1046/j.0306-5251.2001.01527.x 